\title{
Approaches to Digital Profiling in the Financial Market
}

\section{Tatyana Ilina}

PHD, Associate professor in economic sciences

ORCID

E-mail: ilinatg@mail.ru

Tomsk State University, Tomsk, Russia

\section{Elena Piatina}

Assistant

ORCID

E-mail: pyatina_lenaa@mail.ru

Tomsk State University, Tomsk, Russia

Journal of Corporate Finance Research, Vol. 14, No. 4, pp. 47-60 (2020)

DOI: https://doi.org/10.17323/j.jcfr.2073-0438.14.4.2020.47-60

Received 15 October 2020 | Peer-reviewed 23 October 2020 | Accepted 24 October 2020 


\section{Approaches to Digital Profiling in the Financial Market}

\section{Abstract}

Creating a "digital profile" is one of the points of the Russian national program Digital Economy [1]. A single biometric profile creation system is becoming the infrastructure basis for the digital transformation of the entire economy [2]. The process of forming a digital society is associated with the total digitization of all forms and types of relationships. At the same time, it is necessary to take into account the features, threats and trends of this process.

The purpose of this article was to study the essential features and application of digital profiling of the financial market, defining the applications of this method and methodological approaches by examining existing expertise in other areas, and industries.

The article summarizes information about the use of digital profiling in various industries. Areas of the financial market for the application of profiling were identified. The general characteristics are formulated and the features of the development of a methodological approach to profiling in the financial market are revealed. The criteria and principles of forming a digital profile of a market participant, relationships and patterns for improving the models of identification of participants and the market profile as a whole are presented.

Keywords: digital profile, financial market, profiling method, digital identity, identification, digitalization, financial market regulation

JEL classification: E58, G14, G21, G30 


\section{Introduction}

In the circumstances of digital transformation the government role consists in arranging conditions for improving efficiency of advanced technology implementation in financial and non-financial economic sectors. Therein, during transformation it is necessary to ensure a high confidence of population and organizations in innovation technology and its safety. Based on this, the Central bank of the Russian Federation in cooperation with concerned government agencies and financial market participants implements common initiatives for creation and development of financial technology and a digital financial infrastructure.

The information infrastructure built now and represented in the national program Digital Economy gave rise to the notion of "digital profile" which implies a collection of information on individual persons and legal entities stored in the state information systems and furnished to such persons and entities at request and with their consent applying special-purpose digitalized information technology [3]. Thus, the digital profile of a citizen is one of the key components of the digital infrastructure. The Ministry of Digital Development and the Bank of Russia deal with conceptional preparation to its creation.

Development of a digital profile for a certain person or organization will grant access to any information on the profile subject to the user with access to the system which collects and provides data on various profiles. Public authorities act as the principal user of this system.

According to the concept, a digital profile is to consist of such components as: basic data on the profile subject (passport details, Tax Identification Number etc.); data from other national registers in the form of links; list of the profile subject's consents to personal data processing. The draft legislation describing the digital profile concept takes into account the fact that the composition of information stored in the profile is to be determined by the Russian government taking into consideration the necessity to supply data. The digital profile data, first of all, will provide individual persons' and legal entities' identification and rendering of public services.

The single system comprising all profiles in its entirety will be a huge database which may also be used for various types of research and analysis including the financial market analysis.

In financial market studies the digital profiles of the market players performing the main functions will be of interest: direct participants of financial transactions (sellers and buyers of financial instruments, products and services), financial intermediaries and regulators.

The results of research of the financial market digital profile, presented by the authors earlier, addressed the issues of study of various indicators characteristic of the market participants directly involved in financial relations creating the market situation and exerting a significant influence on its development [4]. In the authors' opinion, all these indicators taken together give an opportunity to form a general approach to the digital profile of the whole market.

In view of the aforesaid, the financial market digital profile may be considered as the aggregate of digital profiles of this market participants.

Therefore, in this research we defined the following problems: study of distinctive features and possibility of application of the digital profiling method to the financial market and its participants; determining the scope of application of this method in the financial market after study of its use in other fields and industries.

\section{Materials and Methods}

The digital profiling method is the foundation of the offered methodological approach for creating of a digital profile for a financial market participant.

Profiling is a mix of methods specially developed to assemble and then assess a person's psychological profile. Such profile is made in order to have an opportunity to define fixed-action patterns which may be used in application tasks. Here is an example of application tasks for use of the profile: forecasting of management and HR risks, deception detection; development of models of economic, social, financial and elective behaviour [5]. Various tools used in profiling provide an opportunity to assess impartially human behaviour expressed verbally and non-verbally, evaluate a person's appearance, his / her behavioural preferences and characteristics which allow to predict such person's behaviour in a particular situation in future in other circumstances.

Accumulating experience in application of this method various experts added more tooling which made profiling variable. So, modern profiling methods comprise traditional profiling tools as well as tools related to digitalization.

A digital profile is information electronic media or a special service which stores all data on a person [6].

As a research method digital profiling is a new method derived from common profiling which emerged in the environment of total digitalization while digital economy was formed. Digital profiling stems from engineering sciences as a method of study of digital environment and work with big data which describe various aspects of human relations and society. Therefore, this method is widely applied in practice in social sciences.

Criminology was one of the first social sciences to use the digital profiling method. This method was applied to investigate the cases when one digital device could not be associated with a certain user (use of one device by several users). Later it was applied as a method of making an offender's digital profile by means of studying his / her behaviour, developing a model and analyzing digital footprints. Now, while digital technology is implemented widely, this method serves to counter threats which jeopardize national and public security [7]. 
Gradually the profiling method with different sets of tools including those implying use of digital technology gained popularity and was applied in other human life spheres: aviation and banking [8-10]; human resource management [11; 12]; marketing [13]; education [14-17]; ethnic issues [18-20].

The profiling method is used in management when dealing with human resources, in particular, in control of employment, dealing with psychological climate and personnel performance. Employee profiling implies screening and assessment of candidates as well as analysis of personal characteristics and competencies of the employees working in a company in order to ensure a better job performance in line with the corporate HR strategy. Profiling enables specialists to predict future behaviour of employees in case of emergency or under pressure. It provides an opportunity to define with maximum accuracy employee's "criminal propensity" and the factors which may encourage it.

At present the profiling method applying the tools based on information and digital technology is a new HR tool. Thus, HR professionals use extensively various digital tools such as job sites, social networks and messengers which help to collect and analyze information on a possible candidate in order to make his/her profile to define the job suitability by means of digital screening. So they obtain more unbiased information on the candidate and shorten the time of a job interview with him / her [21]. Also such digital tool as online testing is applied in digital profiling. It enables a candidate to evaluate his / her competencies necessary for the job in the company and the employer - to realize whether the candidate suits for the job on the basis of the testing results [22].

The profiling method in the commercial (banking) field is the basis for banking scoring technology and banking risk assessment. Bank profiling is also applied to reduce credit risks related to crediting losses. Bank profiling is founded on audit and business methodology. In this case on the basis of calculations profiling defines the degree of the credit repayment risk at the time of filing an application and conducting an interview with the borrower. Thus, in banking the profiling method helps to detect the borrower's criminal intent to commit a credit fraud and to define the banking risk degree expressed as a high uncertainty of implementability of the offered business project.

In banking the digital profiling method is applied by an extensive use of digital technology represented in a new format called data mining. This analysis is intended to reveal unknown relationships in the accumulated data, and it is especially important to ensure the bank's competitiveness: credit risk analysis on the basis of the accumulated information on borrowers' credit reputation; customer acquisition by defining the profile of the most profitable customer in the common database; quality improvement of archive information and revealing data insights in archival financial documents, etc. [23].
In education the profiling method is used to make digital profiles of the learning process participants. Digital profiles of the learning process participants facilitate solving the problem of insufficient analytical substantiation for taking pedagogical and management decisions [16]. For instance, in secondary education use of digital technology to gather and process information on the participants helps to build students' digital profiles which display data for tracing an individual development pathway of each student and for comparing their performance to the average figures of the class, group or an educational institution. At the same time the profiling method is applied to create a digital profile of teachers as participants of the education process where the profile data provide an opportunity to evaluate their work [24].

In marketing digital profiling methods are used extensively to study consumers and develop advertising offers (products) on the basis of these profiles. The overwhelming majority of data is collected by cookies (online data) placed on various websites by independent data brokers (for example, Acxiom or Eyeota) [25]. The collected data furnished by data brokers are sold to advertisers in order to target digital advertising to new consumers with which a company has no relations yet, and consequently, of which has no data. Thus, advertisers use the obtained information on digital users in order to profile consumers for marketing purposes [26].

In spite of disputability of use of profiling in the ethnic field this method may also be applied for racial profiling practiced by law enforcement authorities. Racing profiling is use of a person's race or ethnicity by law enforcement officials as a key factor when deciding whether to stop (detain), interrogate or arrest such person if the race or ethnicity is mentioned in the description of certain suspects of a crime [27].

The profiling method is used in aviation in order to prevent terrorist attacks and ensure safety in civil aviation. Aviation profiling implies creation of a passenger profile by study of various features characteristic of a suspicious appearance. A passenger profile is the basis for assigning a person to a certain class according to the degree of danger he/she constitutes [28]. For the purpose of transport safety decisions on additional passengers' inspections are taken on the basis of a passenger profile. In this case profiling provides an opportunity to take preventive measures in order to avoid acts of unlawful interference in operations of civil aviation and other transportation infrastructure facilities.

On the basis of diversity of the considered fields of the profiling method modern uses one can make the conclusion that this method may be applied in any field related to people's interaction and analysis of their behaviour including study of financial relations. Therefore, in order to form a methodological approach and define the possible uses of the profiling method in the financial market we applied the analog method, analysis and synthesis. At the first stage we synthesized the available information concerning the essence and use of digital profiling in var- 
ious fields and industries, then we analyzed the methodological approached applied in these fields determining: the profiling object in each field; its algorithm and stages; criteria and distinctive features of data assessment; the information base necessary for profiling. The third stage of the research is founded on the analog method and reveals the fields in the financial market which by their designation and characteristic features are similar to the industries and fields of profiling application studied before. This led us to the conclusions on the possibilities and uses of profiling in the financial market. At the last research stage, we synthesized the results of the second stage developing the algorithm for elaboration of the methodological approach to profiling in the financial market.

\section{Profiling in Criminology}

The profiling object in criminology is the offender profile. Various tools are used when this method is applied in the abovementioned sphere: conventional and digital ones. They facilitate analysis and assessment of the main components (indicators) of the offender profile.

Three main components are studied when building a criminal profile [7]:

- $\quad$ modus operandi (a way of committing a crime) is a series of actions which characterizes a crime instrument. The way of committing a crime is presented from the functional standpoint of committing a criminal act. So, further one can define the category of a crime;

- social indicators of an individual expressed as emotional-volitional features or psychological constitution which determine the individual's behaviour when the crime is committed;

- pattern in crime represented as a unique combination of behaviour - offender's actions beyond the scope of criminal action functional characteristics and aimed at emotional fulfillment of the person committing a crime.
Additional components of the offender profile assessed by digital profiling are digital footprints and samples. These components show the distinctive features of individual's behavioral signs which are specific for each person. Therein, behaviourial characteristics of an individual are detected regardless of the profiling subject's will [29]. When digital profiling is performed the information, base contains initial information of the crime obtained by analysis of digital footprints and samples, other types of information from chats, blogs, social networks, various forums etc. Individual's interaction with digital environment forms an integral whole in cyberdomain where electronic signals are stored for some time. These signals manifest vestiges of a crime and individual's behavioral signs which serve as indicators constituting the offender profile.

The whole aggregate of crimes and performed actions contains the offender's personal attributes, his/her psychological constitution, social and psychological features of the offender or a criminal group which also create the offender profile.

In criminology profiling has a certain algorithm presented as a sequential actions cycle and consisting of the following stages [30].

1) Defining the profiling purpose - determining the necessary information for a certain case.

2) Data collection and evaluation with the gathered information.

3) Selection of relevant information and subsequent defining of indicators for various areas of exploration.

4) Identifying inconsistencies similarities by means of comparing information indicators.

5) Defining criteria applying comparison methods and building of the offender profile.

6) Analysis of the offender profile obtained by profiling and comparison of this profile to the original purpose.

Table 1 shows characteristics of contents of traditional and digital profiling in criminology [7, p. 391].

Table 1. Characteristics of traditional and digital profiling in criminology

\begin{tabular}{l} 
Profiling stage $\quad$ Traditional profiling $\quad$ Digital profiling \\
\hline
\end{tabular}

Data collection
Obtaining information on circumstances of a crime; facts; evidence represented by photos and video records; witnesses' statements
Collecting information on the system structure; electronic data; data obtained by means of promising hypotheses
Working out a solution applying the processed data collected at the previous stage
Data systematization by means of classification schemes and tables
Data transfer to a file journal; data processing and program analysis; categorizing; development of an offender model for identification 


$\begin{array}{lll}\text { Profiling stage } & \text { Traditional profiling } & \text { Digital profiling } \\ \begin{array}{lll}\text { Criminal actions evalu- } \\ \text { ation }\end{array} & \begin{array}{l}\text { Reconstruction of behaviour of the indi- } \\ \text { vidual who committed criminal actions, } \\ \text { and of behaviour of the individual who } \\ \text { was the victim of criminal actions }\end{array} & \begin{array}{l}\text { Evaluation of characteristics of the digital } \\ \text { device used for criminal actions; assessment } \\ \text { of crime methods and instruments; evaluation } \\ \text { of interaction of means and methods of crime. } \\ \text { Defining behaviourial characteristics of the } \\ \text { offender }\end{array}\end{array}$

Offender profiling

Modelling of the initial profile on the basis of collected and processed information. Following clues of the crime. Logical analysis and reconstruction of the crime by obtaining new knowledge about it
Modelling of the offender profile for correlation and comparison to suspects. Profile updating on the basis of the information obtained at this stage of correlation
Data mining and link analysis. Detecting stable, typical, information and psychological relations by the artificial intelligence method

Investigation

Universalization and optimization of the link analysis data. Detailed elaboration of structural elements and their relations defined at previous stages. Use in the investigation of the information obtained in the form of processed behaviourial data.

Feedback

Table 1 displaying profiling stages shows that traditional and digital profiling in criminology apply methods of offender's modelling rather similar in their essence. But it should be noted that at the same time the means applied to achieve the goal are different.

The digital profiling method requires a particularly complex intellectual activity in criminology. The main challenges of its use which determine its distinctive features are as follows:

- incomplete compliance and incomplete documenting of certain problematics;

- difficulty of consolidation of data related to human nature and the data inserted by informatics;

- doubtfulness of the data obtained as a result of a psychological investigation and traditional criminalistic profiling.

Criminalistic profiling is distinctive in creation of various versions of behaviour when committing a crime, identifying of the causes of such criminal behaviour and its nature. Various means and knowledge of criminal sciences are used to generate and identify data applying criminalistic profiling.

\section{Profiling in management - human resource management (HR sphere)}

In HR management the object of profiling is candidates' profiles and company employees' profiles. Just as in criminology, HR profiling is performed using traditional and digital tools.

In traditional profiling candidates are assessed by means of a direct contact with an individual in order to obtain necessary information for making the candidate profile, in other words, an interview. During an interview human behaviour is assessed and predicted by psychological methods. The information furnished by the candidate (direct answers) is used as the information base to form candidate's profile indicators. The data collected for study of the indicators which form the candidate's profile comprise the psychophysiological state, stress resistance; expertise level needed for the job; person's trustworthiness.

In order to obtain unbiased information from a candidate projective techniques are used to ask questions during the interview, thus, creating his / her profile. The projective technique is a methodology of asking questions in such a way that the question formulation makes a person to answer unconsciously on the basis of his / her personality characteristics and experience which ensures the maximum truthful information.

In order to get unbiassed information and build a full candidate's profile additional techniques of information collection are also applied, including digital profiling. Various digital tools are used for digital profiling (job sites, social networks etc.) where additional information may be gathered beforehand which will form an unbiassed candidate's profile. Thus, various publicly available information resources and databases are used for HR digital profiling. All publicly available information about an individual (photos, posts, reposts, personal information in the profile, number of friends etc.) published and written by a person in social networks is studied. On the basis of all collected data a conclusion is made of the person's view of the world, experience, personal values and beliefs.

Information from search systems (Yandex, Google etc.) where all digital footprints are traced using the individual's personal details (full name, telephone, e-mail) is used as a digital tool in digital profiling of a candidate. Digital footprints give useful information characteristic of a per- 
son, for example, attitude to lawsuits with the companies by which he / she has been employed.

The federal site of judicial enforcement officers is also a publicly available source used to build the candidate's profile. It provides information on the candidate's orders of enforcement and outstanding debts, distrained property and unpaid traffic fines on the basis of the region of residence and full name. This characterizes the candidate's attitude to his/her obligations and a probable risk factor in case of use / borrowing of third parties' funds.

In HR profiling user pages in social networks are analyzed. In order to achieve the most reliable, quick and complete result of this analysis HR specialists use customized applications for person's (candidate's) profiling and further assessment. Profiling applications in social networks are mainly automated which saves HR specialist's time. Automated applications used to analyze social media pages are publicly available.

Automated applications for page profiling are as follows: Cambridge, VK LikeChecker, socialdatahub etc. These servers grant access to databases of social network users as quantitative data on direct conversions, selected posts according to specified criteria, quantitative information on reposts, likes and total account activity. Such databases provide an opportunity to evaluate various types of statistics on a certain network user.

The indicators used to analyze a person's profile in social networks may be presented as follows [31]:

- time of attendance (activity) of social networks: number of pages and online time;

- location of the user's electronic device (geolocation);

- $\quad$ tagging of marks at web pages and posts topics;

- personal information provided in social networks (personal information, career, social status, interests etc.);

- publicity of the social profile.

Thus, when analyzing a person's profile in social networks study of all abovementioned indicators allows to assess congruence of the data stated in the curriculum vitae and to build an initial profile of a certain user as a prospective candidate. Further it may serve as a criterion for assessment of the created profile.

The president of ANO Scientific Research Center of Corporate Seciruty, profiler-polygraphologist Anna Kulik presented and described the following stages of human resources profiling [32].

$1^{\text {st }}$ stage - making the list of candidate's specifications (defining criteria to assess the candidate's profile).

$2^{\text {nd }}$ stage - search for and analysis of candidates (CV) on the basis of the specifications defined at the previous stage.

$3^{\text {rd }}$ stage - contact with the candidate to analyze and assess his / her personality (candidate profiling).

When HR profiling of company employees is performed salary indicators, working hours and employee's file (education, length of employment etc.) are studied, as well as estimated figures related to employees' skills and their personal characteristics (KPI (key performance indicators)).

\section{Profiling in marketing}

Profile of a potential consumer of goods, works or services planned for advertising is the profiling object in marketing [36].

Marketing profiling, similar to bank profiling is the foundation for development of customized offers of goods and services. In banking it is represented by credit proposals (period, amount etc.), in marketing - by other product or services offers.

Information on consumers for marketing profiling is obtained in various ways used by data brokers. Data brokers (or information brokers) are companies engaged in gathering and sale of information on people represented as their personal information. Data broker companies started developing and collecting actively information for consumer profiling in the age of progress of Internet and digital services which provide public access to huge amounts of information. Currently there is a great number of companies acting as information brokers.

USA legislation in accordance with the Data Privacy Protection Act allows data brokers to use a huge amount of information attributes about a person. In the European Union data brokers comply with law taking advantage of network users' carelessness in executing their user agreements.

The information collected by data brokers comprises information on location (users' addresses), personal property (owned vehicles), personal data from social networks, online shopping history and transaction bank operations using bank cards and search and watch history of web sites.

Data brokers gather data from various publicly available Internet sources and also purchase data from government agencies and organizations furnished by commercial companies which store information on their customers.

Personal information on people (prospective consumers) collected and arranged by data brokers may be conventionally divided into two groups [37].

1) Information obtained by hacking special protection of the sites of retail and maintenance service companies.

2) Data stated by web site visitors when they fill in personal pages and questionaries.

The unified database created and aggregated by the so called data brokers serves as the information base for marketing profiling.

Consumers' profiling by data brokers consists of the following stages [13].

1) Information collection by data brokers on persons (prospective consumers) from various web sites (Internet resources). 
2) Synthesizing of the collected information on consumer's visits into anonymized user profiles.

3) Making conclusions on consumers on the basis of heuristics and machine learning and consumer profile identification according to various criteria (gender, age, interests etc.).

4) Gathering the audience as an aggregate of various persons' profiles to sell it to advertisers in order to target digital advertising to new consumers.

Thus, potential consumers' profiling provides an opportunity to generate more personal ideas for people from the audience gathered for a certain commercial offer in the market and allows to arrange communication with a consumer in order to attract attention to the product or service.

\section{Profiling in education}

In education the object of the profiling method is a student and teacher profile.

In order to create a student and teacher profile the following basic data are used which currently are gathered in the database of the Electronic Diary for secondary schools [24]:

- student's personal information (student's unique identifier);

- year;

- teacher's personal information (teacher's unique identifier);

- taught subjects / disciplines;

- dates, lesson topics;

- knowledge assessment forms and the result.

Students are profiled by applying the comparative analysis to their performance comparing it to the class and the cohort of students. Such comparison is called a T-criterion comparison. The Student's statistical T-criterion comparison provides a visual display of obtained data in diagrams. The diagrams visualize student's performance in comparison to the class and cohort and they show trends in performance on the basis of the linear regression method. Thus, due to study of the student's performance diagrams conclusions are made on the causes which influence improvement or decline in performance: influence of the student's personal characteristics on knowledge absorption and school performance or a poor education level. It should be noted that performance diagrams allow to define advisability of use of mean values performance triggers for each subject. As a result, the obtained and analyzed data provide an opportunity to develop special recommendations to deal with a student's individual learning trajectory which is the main component of his / her learning profile.

So, the student learning profile created on the basis of the Electronic Diary allows to solve the following problems:

- monitoring of the data indicative of the student's performance, presented in the detailed description of performance by subjects with a possibility to specify target values;

- compiling of students' rating according to their performance in classes and cohort on the basis of statistical performance comparisons presented in the detailed description of performance by subjects by means of the T-criterion method;

- defining the students' performance trend using the regression analysis algorithms.

In order profile a teacher inner and external analysis of the grades assigned by this teacher are conducted. The inner analysis is carried out on the basis of the grades on the subjects with a breakdown by the cohort, average grades and in comparison to performance of classes all over the school. The external analysis is conducted on the basis of the average grades comparison algorithms and a variety of grades given by the teacher taking into consideration various knowledge assessment forms.

Teacher profiling allows to obtain data important for the headmaster who, in his/her turn, has an opportunity to control teachers' performance using the collected data. As a result, an education environment participant's profile provides an opportunity to solve the problem of insufficient analytical substantiation of pedagogical and management decisions.

\section{Profiling in aviation}

In aviation (transportation) a passenger profile is the object of the profiling method.

In aviation profiling the following fields of application of this method may be defined: preflight inspection in an airport; questioning of passengers undergoing an inspection; surveillance of the psychological state of passengers etc.

The stages of profiling in transportation are as follows [28].

1) Initial surveillance of a passenger to define his / her characteristics and suspicious behaviour, identify alerting signs. The initial surveillance allows to define beforehand the passenger's type by the flight purpose (business trip, tourism etc.). Thus, initial conclusions about the observed passenger are made at the first stage.

2) Inspection of documents for identity check and defining the reliability and validity of submitted data.

3) Interview with a passenger showing suspicious signs registered at the previous stages in order to define whether it is necessary to conduct additional inspections for suspicious behaviour and security threat.

4) Questioning the passenger showing suspicious signs in order to solve existing doubts and to get answers to the questions the profiling aviation officers have.

5) Characterizing the passenger taking into consideration the information obtained at the previous stages: passenger classification according 
to safety categories and threat level. Development of further security measures as regards the passenger taking into consideration the assigned classification. Passengers classification is made in accordance with their transport threat level established by profiling. So, there are low, normal, high and extremely high risk passengers. On the basis of the defined risk level of a certain passenger a decision is taken on additional safety measures to be taken by the security service and law enforcement authorities in order to adopt the final resolution on the passenger's involvement in a planned terrorist attack or an act of unlawful interference.

\section{Racial profiling}

In spite of the increasing popularity of this research field a series of methodological and theoretical problems impede it. The main problem is complexity of empiric detecting of racial disbalance in the work of law enforcement authorities related to the continuing search for a reliable "denominator" and insufficiency of simple establishing of racial disproportion for an unambiguous conclusion on existence of racial profiling. As long as in a significant part of research the abovementioned limitations have not been taken into consideration and the conclusions are extremely hasty one should be very careful when using them [38]. For this reason, we eliminated the racing profiling method from a detailed study and abstained from its use in development of the methodology.

\section{Discussion}

Analysis showed that in spite of an extensive use the theoretical and methodological basis of the digital profiling method has been studied and described in a piecewise way and is scarcely used in the financial market. Therein, the behavioural finance theory places high emphasis on study of the personality characteristics system and financial behaviour. Therefore, on the basis of lessons learnt and research for use of profiling in various fields we defined the general principles of the profiling algorithm and found similar fields and opportunities of its use in the financial market.

As was already mentioned, the essence of the "digital profiling" method consists in automated collection and electronic processing of data from huge information arrays on the basis of a previously selected set of characteristics of the studied object's profile. As we established, the characteristics studied when creating the profile depend on the type of studied relations. When the financial market is studied financial relations are analyzed, therefore it is necessary to take into consideration their characteristics and distinctive features. At the same time, apart from the specific features, inherent only in a certain type of relations one should take into consideration general features which are basic and define the profile subject's behaviour type. Such features comprise: life and occupational experience, social roles, volitive and moral, intellectual and emotional characteristics [7].
Literature emphasizes that currently scientific theory does not define the components of a profile. Nevertheless, its three most important components are determined as follows:

- means and methods of relations fulfillment which define the role, functions and actions of an individual in such relations (depending on occupational and other specific skills, knowledge and resources in this field etc.);

- social and economic characteristics of the studied object;

- unique behaviour combinations, as a rule, defined by a unique experience of relationship with other individuals and personal attributes as well as by response to changes and procedures.

Consolidation of the existing approaches to profiling in various fields allowed us to determine its main stages:

1) defining the profiling goal (the most important information types, distinctive features and characteristics of the studied object in accordance with the type of relations and environment of their fulfillment);

2) collection and evaluation of the data containing the information necessary for profiling by means of study of the information base;

3) selection of the information pertinent to the studied field and defining specific indicators;

4) determining differences and similarities by correlation of relevant information in comparison to indicators;

5) making the list of the most significant criteria on the basis of which the system of qualitative and quantitative indicators is created - building the "digital profile" model on the ground of the basic elements by means of mental or logical, mathematical or cybernetical modeling, reconstruction;

6) analysis and monitoring of the digital profile in order to reveal and predict the trends and changes as well as to assess it against the initial goal.

On the basis of the profiling stages, this method algorithm is as follows:

1) setting the profiling goal;

2) choosing the profiling object;

3) profiling planning (tools, applied methods etc.);

4) defining the profiling subject (who and why will perform profiling);

5) information collection and processing for profiling on the basis of the predetermined goal;

6) selection, systematization, classification and analysis of the collected data;

7) finalizing of profiling findings, creating profiles and formulating conclusions, developing recommendations and proposals. 
Study of various fields of the method application showed that usually the accumulated databases on profiling objects (data on customers, employees, offenders etc.) are used as the information base.

Besides the main information sources are: publicly available information resources and databases represented by search systems and web pages with a huge amount of information concerning page users and digital footprints which remain as a result of interrelation executed through communication channels of an individual (digital user) and digital environment as the integral whole in cyberdomain. The databases created by means of pretesting / questionnaire survey of a certain group of people are extensively used as the information base.

The information selection criteria for profile creation in each field are extremely specific and defined on the basis of the initial goal formulated at the initial stage. Therefore, in order to determine correctly the profiling criteria in a certain field, first of all, the expected results are to be defined. All data collected for profiling may be divided into several levels from the point of view of such result [6].

The first level - the data collected by online services without the customer's consent ("uncontrolled" data used to take decisions on possible interaction ways).

The second level - information on the customer's behaviour in the digital space, metadata (location, content he / she is interested in, keystroke dynamics etc.) which may be the foundation for studying the personality, temperament, inclinations, customer's attitude to certain things. The third level - secondary data selected on the basis of the algorithmic analysis and comparison to the data on other customers. It provides an opportunity to reveal underlying behavioral factors such as weaknesses, intelligence level, dependences, intentions, obsessional ideas etc. Such information on subconscious mechanisms and automatic responses in customers' behaviour may be used to create informed needs, encourage to take decisions.

Approaching the problem of profiling in the financial market it is necessary to emphasize that the field of finance is in the process of a drastic technology transformation and restructuring as well as transfer to the customer-oriented platform model which implies use of digital algorithmic methods of information processing already applied in some segments [39; 40].

In particular, in the credit market the profiling object is a profile of the bank customer who intends to receive a banking service or who has already received it. In banking profiling is performed by means of data mining. Depending on the type of initial information and the method of data extraction from such information this type of analysis is divided into analytical, visual and text data mining.

The profiling methodology in the commercial sphere comprises algorithms of matching of the customer profile to typical product packages in order to ensure a system-level functioning of procedures of product sales to the customer audience and in order to improve products on the basis of analysis of real and automatically created customer profiles.
A bank customer profile comprises the following data (indicators): customer location, age; education level; marital status, occupation; level of problems which dictates the need to receive a banking service; level of spending funds within a certain period; way of thinking and logic of taking decisions on funds spending; level of knowledge on bank products; level of readiness to purchase the service / bank product.

For digital profiling of a bank customer the following indicators are studied additionally:

- level of awareness and use of digital devices;

- level of readiness to furnish information on oneself (personal information) by means of digital technology (digital trust) [33].

Customers are classified using customer profiles created on the basis of the indicators described above. Such classification is used for segmentation of the customer base and further development of successful proposals of bank products and services.

Profiling in banking is applied to define customer (prospective borrower) insolvency probability. In this case profiling is performed by means of scoring. Scoring is a method of dividing prospective borrowers (bank customers) into groups on the basis of some variables characteristic of them: borrower's personal information and credit history (amounts of previous loans, timeliness of repayment, delays in payment etc.).

The aggregate of all information collected about the borrower provides an opportunity to create his / her profile and make the final estimate of his/her creditworthiness. So, the profile estimate allows to classify the borrower and define the decisions as regards granting him / her a loan.

Creditworthiness of a prospective borrower is determined by means of the data mining system on the basis of retrospective information which allows by means of classification to detect a borrower who has repaid or has not repaid the loan in prior periods. Thus, all bank customers are divided into two groups: the ones who have repaid loans and the ones who have not. Each group provides an opportunity to define the borrower's main signs of potential non repayment. It helps to assess beforehand the collected information on a new customer and to assign him / her to a certain group.

As a consequence, the data mining tools allow to do customer profiling, i.e. classify customers as "good" and "bad" borrowers. Customer classification according to groups of non-repayment risk has a direct effect on solving the problems of defining individual credit terms for a customer (credit limits, interest rate level, loan term etc.).

Currently innovations are introduced in banking scoring in the form of borrower psychographic profiling. The innovation consists in use of new efficient methods of borrower profile creation applying a non-conventional evaluation of bankruptcy probability. This innovative method is offered by VisualDNA which is the leader in the market of data analysis. VisualDNA developed a 
unique technology of psychographic profiling of financial organizations' customers in order to predict their bankruptcy probability. The technology was founded on the studies in the field of personality development and human behavior psychology.

The main advantage of the VisualDNA technology which offers its own rating of borrowers is no need in credit history information for a person's profiling. The VisualDNA profiling technology implies use of psychographic data obtained by testing. Such data provide an opportunity to influence the quality of scoring models performance maximizing the profit of financial organizations without increase of risk.

The psychographic profiling by means of the VisualDNA technology consists of the following stages [33]:

1) customer testing and data collecting on a prospective borrower;

2) automated processing of data using the VisualDNA program followed by forming of the result;

3) entry of data into the scoring model together with the data on the borrower's credit history;

4) forming of the final profiling result: VisualDNA borrower rating (profile).

It should be noted that the tools of the profiling method in banking are applied to the borrowers - individual persons and to the borrowers - legal entities. The profiling methodology for individual persons and legal entities when evaluating their creditworthiness differs.

When profiling tools are applied to legal entities corporate creditworthiness indicators are used and analyzed. They provide an opportunity to further classify the company and assign it to a certain category.

At the initial stages of legal entities profiling all documents of the prospective corporate borrower are studied to determine the customer's ability and readiness to repay the loan in full within the period established by the bank. In this case corporate legal documents which describe the company operations and certify their legitimacy are studied as well as financial documents which form accounting (financial) reports [34].

All data collected from legal and financial documents of a legal entity are assessed by the creditworthiness criteria represented by corporate liquidity indicators. On the basis of comparison of the obtained values to the specified criteria a legal entity is assigned a certain category for further creation of the company profile and taking the decision on granting or rejecting a loan by the bank.

Usually the following categories (classes) of borrowers legal entities are defined: prime-quality borrower; limited creditworthiness borrower; insolvent borrower [35]. So, the profiling method of a borrower - legal entity on the basis of the scoring model enables a credit organization to evaluate creditworthiness of its customers and minimize its credit risks by means of taking reasoned decisions on granting loans.
Study of financial behaviour of USA higher education institutions on the basis of the multilevel latent class analysis revealed the opportunity to create and trace profiles of their income and expenditure in a changeable environment. This confirms the possibility of applying digital profiling for study of financial relations participants which are legal entities and entrepreneurs [41]. Therein, researchers of corporate lending risks on the basis of hybrid neural networks and fuzzy models emphasize that it is necessary to use a unified procedure of choosing corresponding indicators in order to reduce the degree of uncertainty and noise in publicly available data on the basis of such methods as credit scoring, neural modeling, fuzzy logic model etc. [42]. This confirms the necessity of developing a unified methodological approach.

In insurance algorithmic profiling is used to generate individual insurance policies, to assess risks and pay premiums on the basis of study of the behaviour of the insured. But according to specialists availability of individual information may have a negative effect on the insurance fundamental principles based on risk aggregation, distribution and interinfluence within the insuring parties' pool as well as cause unjustified discrimination of customers [43]. In scientists' opinion, this concern should not be considered for a single financial market segment but within the whole social medium. So, they make the conclusion that it is necessary to develop and introduce special limitative methods of anti-discriminatory regulation including financial regulation. Therein the issues of protection of rights of non-professional market participants and customers become of primary importance [39; 45].

Analysis of the credit and insurance sectors showed that mainly digital profiling is applied in the activities related to elevated risk. Preconditions depend on the interests of the financial market participants and their need to obtain more diversified and higher quality services by means of digitalization [46]. The conclusion on the necessity to monitor risks is confirmed in various scientific papers [39; 40 ; 42-44; 46; 47].

In order to reveal the possibilities of use of the digital profiling method in the financial market we applied the analog method which laid the main emphasis on the results of analysis of the profiling method application in other fields.

Currently one of important behaviourial characteristics of the financial market participants is their financial literacy which influences investment activity, and consequently, in the long run defines the demand in the market. Therefore, in this case we can apply the profiling experience from the education sector to the financial market. The financial market participants' - financial services consumers' - profile is the profiling object. The results will serve as a source of information for the World Bank, Central Bank of the Russian Federation, Ministry of Finance of the Russian Federation not just to assess the degree of population's financial literacy but also to monitor the investment behaviour in the financial market. Further this will provide an opportunity to develop an efficient regulatory policy. 
Therein the main methods and tools for data collection and indicators forming may be questionnaire survey (testing) when signing up at special sites (for example, fincult. $\mathrm{ru}$ ) and conducting trainings for improvement of financial literacy. The collected data will be processed by means of correlation, comparison and classification. The information may be registered in an electronic journal.

The profiling method from criminology may be applied to study fraud and crimes in the financial market where the seller (credit / financial organizations) along with the customer will be the research object. In this case profiling will be a source of information for the financial market regulator as well as for law enforcement authorities in order to avoid the risk of theft and loss of funds in the financial market and to improve efficiency of the market regulation.

When market participants are profiled for fraud the information base for data collection will be as follows: applications and evidence from the police database concerning fraud in the financial market as well as defrauders' digital footprints gathered by means of study of cyberdomain for behaviour of defrauders, fraud procedure, cyber locations of fraud and ways of performing operations.

\section{Conclusion}

Study of digital profiling issues is important for science, society, business and each individual because it has an ever increasing influence on various fields of economics and finance. Creation of a digital profile in the financial market is a significant issue for all its participants: professionals and non-professionals, individual persons and legal entities as well as for regulators. A variety of financial relations preconditions different versions and possibilities of its use. Experience suggests that it is necessary to take into consideration the risks related to personal, social and national security. Therefore, each market participant has to study to create and control a digital profile at the micro and macro level. A unified methodological approach to digital profiling is necessary to create the digital identity culture. Also, clear and available rules which enable the market participants to control fully digital data and their own digital projection are necessary.

The methodological approach to financial market profiling allows to create the financial market profile on the basis of its participants' profiling. We offer to consider the financial market profile as an aggregate of participants' digital profiles which provides a general characteristic of the market as a whole. Such approach allows to describe "unaccounted" aggregate digital characteristics of the market using unofficial information sources. Application of this approach provides an opportunity to obtain a digital "portrait" of a certain participant, segment or level of the financial market. Therein it is possible and necessary to use experience from other fields and sectors in order to expand the method application in the financial market taking into consideration the distinctive features and trends of its development.

\section{References}

1. "Digital profile": Demanded by banks, convenient for customers. NBJ: National Banking Journal. May 20, 2020. URL: http://nbj.ru/publs/aktual-najatema/2020/05/20/tsifrovoi-profil-vostrebovanbankami-udoben-dlja-klientov/ (accessed on 20.11.2020). (In Russ.).

2. Text of the bill on digital profiles of Russians. Federal portal of draft normative legal acts. URL: https:// regulation.gov.ru/projects\#npa $=89871$ (accessed on 20.11.2020). (In Russ.).

3. National program "Digital economy of the Russian Federation" dated Dec. 24, 2018. URL: http:// government.ru/rugovclassifier/614/events/ (accessed on 24.11.2020). (In Russ.).

4. Pyatina E.A., Ilina T.G., Tyuleneva N.A., Khabibulina A.N. Analysis of digital profile of the financial market: A methodological approach of Russian Central Bank. SHS Web of Conferences. 2020;80:01023. DOI: $10.1051 /$ shsconf/20208001023

5. Foygel E.I., Kozuleva A.A. Using profiling in the operational, investigative and expert activities. Sibirskie ugolovno-protsessual'nye i kriminalisticheskie chteniya $=$ Siberian Criminal Process and Criminalistic Readings. 2015;(2):223-233. URL: https://cyberleninka.ru/article/n/ispolzovaniemetoda-profaylinga-v-operativnoy-sledstvennoy-iekspertnoy-deyatelnosti (accessed on 07.12.2020). (In Russ.).

6. Kondakov A.M., Kostyleva A.A. Digital identity, digital self-identification, digital profile: Problem statement. Vestnik Rossiiskogo universiteta druzhby narodov. Seriya: Informatizatsiya obrazovaniya $=$ RUDN Journal of Informatization in Education. 2019;16(3):207-218. (In Russ.). DOI: 10.22363/23128631-2019-16-3-207-218

7. Sukhodolov A.P., Kaluzhina M.A., Spasennikov B.A., Kolodin V.S. Digital criminology: The method of digital profiling of an unidentified criminal's behavior. Vserossiiskii kriminologicheskii zhurnal = Russian Journal of Criminology. 2019;13(3):385-394. DOI: 10.17150/2500-4255.2019.13(3).385-394

8. Leenes R.E. User-centric identity management as an indispensable tool for privacy protection. International Journal of Intellectual Property Management. 2008;2(4):345-371. DOI: 10.1504/ IJIPM.2008.021431

9. Luffarelli J., Markou P., Stamatogiannakis A., Gonçalves D. The effect of corporate social performance on the financial performance of business-to-business and business-to-consumer firms. Corporate Social Responsibility and Environmental Management. 2019;26(6):1333-1350. DOI: $10.1002 / \mathrm{csr} .1750$ 
10. Pop C., Georgescu M.-A. Credit enhancements and the Romanian municipal bond market. Transylvanian Review of Administrative Sciences. 2016;(48):104-123.

11. Harrison J.A., Budworth M.-H. Unintended consequences of a digital presence: Employmentrelated implications for job seekers. Career Development International. 2015;20(4):294-314. DOI: 10.1108/CDI-06-2014-0080

12. Pybus J. Social networks and cultural workers: Towards an archive for the prosumer. Journal of Cultural Economy. 2013;6(2):137-152. DOI: $10.1080 / 17530350.2012 .742850$

13. Neumann N., Tucker C.E., Whitfield T. Frontiers: How effective is third-party consumer profiling? Evidence from field studies. Marketing Science. 2019;38(6):918-926. DOI: 10.1287/mksc.2019.1188

14. Siso-Calvo B., Arquero-Avilés R. Plataformas digitales y reputación académica: Análisis del área de Biblioteconomía y Documentación en España. Ibersid. 2020;14(1):69-77.

15. Guerin C., Aitchison C., Carter S. Digital and distributed: Learning and teaching doctoral writing through social media. Teaching in Higher Education. 2020;25(2):238-254. DOI: $10.1080 / 13562517.2018 .1557138$

16. Masterson M. An exploration of the potential role of digital technologies for promoting learning in foreign language classrooms: Lessons for a pandemic. International Journal of Emerging Technologies in Learning. 2020;15(14):83-96. DOI: 10.3991/ijet. v15i14.13297

17. Sivanesan S. Alex \& I: Narrative and network resistance. Social Identities. 2019;25(4):559-572. DOI: $10.1080 / 13504630.2018 .1514161$

18. Adams N.B., DeVaney T.A. Digital ethnicity Emerging profiles. In: CELDA 2019: $16^{\text {th }}$ Int. conf. on cognition and exploratory learning in digital age (Cagliari, 7-9 Nov. 2019). International Association for Development of the Information Society; 2019:435-438.

19. Lee M.F. Exploring learners' digital profile among the youth. In: 2016 IEEE conf. on e-learning, e-management and e-services (IC3e) (Langkawi, 10-12 Oct. 2016). New York: IEEE; 2017:91-95. DOI: 10.1109/IC3e.2016.8009046

20. Vlachopoulos D., Pitsiavas D. The digital profile of primary school principals: Achieving effective educational administration through ICT. International Journal of Educational Organization and Leadership. 2016;23(3):17-28. DOI: 10.18848/23291656/CGP/v23i03/17-28

21. Martynova M.E., Kamshilov S.G. Digital technologies in personnel management of the company.
Obshchestvo, ekonomika, upravlenie = Society, Economy, Management. 2019;4(4):69-74. URL: https://cyberleninka.ru/article/n/tsifrovye-tehnologiiv-upravlenii-personalom-kompanii (accessed on 01.12.2020). (In Russ.).

22. Yavorskii N.K. Digital technologies in the personnel management system. Molodoi uchenyi = Young Scientist. 2020;(19):260-262. URL: https://moluch. $\mathrm{ru} /$ archive/309/69896/ (accessed on 02.12.2020). (In Russ.).

23. Rudskaya E.N., Poltavskaya Yu.Yu. Profiling the digital customer: New formats in intellectual data analysis. Molodoi uchenyi = Young Scientist 2015;(21):464-471. URL: https://moluch.ru/ archive/101/22843/ (accessed on 02.12.2020). (In Russ.).

24. Samborskaya L.N., Myasnikova L.A. The main methods of constructing the "digital profile" model using the example of Moscow schools. Interaktivnaya nauka = Interactive Science. 2017;(3):68-86. URL: https://cyberleninka.ru/article/n/osnovnye-metodypostroeniya-modeli-tsifrovoy-profil-na-primereshkol-g-moskvy (accessed on 03.12.2020). (In Russ.).

25. De Bruyn A., Otter T. Bayesian customer profiling: Applications to age and political partisanship estimation. SSRN Electronic Journal. 2016. DOI: $10.2139 /$ ssrn.2740293.

26. Trusov M., Ma L., Jamal Z. Crumbs of the cookie: User profiling in customer-base analysis and behavioral targeting. Marketing Science. 2016;35(3):405-426. DOI: 10.1287/mksc.2015.0956

27. Bikeeva E.S. The concept of racial profiling and the problems of its use in law enforcement. Vestnik YuzhnoUral'skogo gosudarstvennogo universiteta. Seriya: Pravo = Bulletin of the South Ural State University. Series "Law". 2011;(40):42-43. URL: https://cyberleninka. ru/article/n/ponyatie-rasovogo-profilirovaniya-iproblemy-ego-ispolzovaniya-v-pravoohranitelnoydeyatelnosti (accessed on 03.12.2020). (In Russ.).

28. Vozjenikova O.S., Kuznetsov D.A. Profiling technology in the field of aviation (transport) security. Nauchno-metodicheskii elektronnyi zhurnal Kontsept $=$ Scientific and Methodological Electronic Journal “Concept". 2014;(12):176-180. URL: http://ekoncept.ru/2014/14368.htm (In Russ.).

29. Colombini C.M., Colella A. Digital scene of crime: Technique of profiling users. Journal of Wireless Mobile Networks, Ubiquitous Computing, and Dependable Applications. 2012;3(3):50-73. URL: http://isyou.info/jowua/papers/jowua-v3n3-4.pdf

30. Butenko V. Relevance of using the profiling method in the investigation of serial rapes. In: Topical issues of jurisprudence. Proc. $5^{\text {th }}$ Int. sci.-pract. conf. Penza: Nauka i prosveshchenie; 2018:50-52. (In Russ.). 
31. Galanova E.V. Personality profiling based on the analysis of its social media account. Innovatsionnaya nauka = Innovation Science. 2019;(2):58-61. URL: https://cyberleninka.ru/article/n/profilirovanielichnosti-na-osnove-analiza-ee-akkaunta-vsotsialnyh-setyah (accessed on 06.12.2020). (In Russ.).

32. Official website of Anna Kulik, president of Research Center for Corporate Security. URL: https:// anna-kulik.ru/category/profajling/ (accessed on 06.12.2020). (In Russ.).

33. Rudskaya E.N., Poltavskaya Yu.Yu. Borrower profiling technologies in banking: Innovations in scoring and minimizing fraud risks. Molodoi uchenyi $=$ Young Scientist. 2015;(24):567-574. URL: https://moluch.ru/ archive/104/24447/ (In Russ.).

34. Giannopoulos V., Aggelopoulos E. Predicting SME loan delinquencies during recession using accounting data and SME characteristics: The case of Greece. Intelligent Systems in Accounting, Finance and Management. 2019;26(2):71-82. DOI: 10.1002/ isaf. 1456

35. Makaeva A.M., Sharif'yanova Z.F. Credit scoring as a tool for effective assessment of the creditworthiness of a commercial bank borrower. Innovatsionnaya nauka = Innovation Science. 2016;(4-1):202-207. (In Russ.).

36. Kim Y., Street W.N., Russell G.J., Menczer F. Customer targeting: A neural network approach guided by genetic algorithms. Management Science. 2005;51(2):264-276. DOI: 10.1287/mnsc.1040.0296

37. Murthi B.P.S., Sarkar S. The role of the management sciences in research on personalization. Management Science. 2003;49(10):1344-1362. DOI: 10.1287/ mnsc.49.10.1344.17313

38. Grigoryeva K.S. Racial profiling: The history and current state of research. Demograficheskoe obozrenie = Demographic Review. 2019;6(4):104-127. URL: https://cyberleninka.ru/article/n/rasovoeprofilirovanie-istoriya-i-sovremennoe-sostoyanieissledovaniy (accessed on 07.12.2020). (In Russ.).

39. Vives X. Digital disruption in banking. Annual Review of Financial Economics. 2019;11:243-272. DOI: 10.1146/annurev-financial-100719-120854

40. Romānova I., Kudinska M. Banking and fintech: A challenge or opportunity? In: Grima S. et al, eds. Contemporary issues in finance: Current challenges from across Europe. Bingley: Emerald Group Publ. Ltd.; 2016;98:21-35. (Contemporary Studies in Economic and Financial Analysis Series). DOI: 10.1108/S1569-375920160000098002
41. Barringer S.N. The changing finances of public higher education organizations: Diversity, change, and discontinuity. In: Berman E.P., Paradeise C., eds. The university under pressure. Bingley: Emerald Group Publ. Ltd.; 2016:223-263. (Research in the Sociology of Organizations. Vol. 46). DOI: 10.1108/S0733558X20160000046008

42. Gorbatkov S., Farkhieva S. Bankruptcy risk assessment in corporate lending based on hybrid neural networks and fuzzy models. Korporativnye finansy $=$ Journal of Corporate Finance Research. 2016;13(1):28-39. DOI: 10.17323/j.jcfr.20730438.13.1.2019.28-39

43. Cevolini A., Esposito E. From pool to profile: Social consequences of algorithmic prediction in insurance. Big Data \& Society. 2020;7(2). DOI: $10.1177 / 2053951720939228$

44. Mann M., Matzner T. Challenging algorithmic profiling: The limits of data protection and anti-discrimination in response to emergent discrimination. Big Data \& Society. 2019;6(2). DOI:10.1177/2053951719895805

45. Kharisma D.B. Urgency of financial technology (Fintech) laws in Indonesia. International Journal of Law and Management. 2020. (In print). DOI: 10.1108/IJLMA-08-2020-0233

46. Maramygin M.S., Chernova G.V., Reshetnikova L.G. Digital transformation of the financial services market in Russia: Trends and specificity. Upravlenets = The Manager. 2019;10(3):70-82. (In Russ.). DOI: 10.29141/2218-5003-2019-10-3-7

47. Chernyakov M., Chernyakova M. Technological risks of the digital economy. Korporativnye finansy $=$ Journal of Corporate Finance Research. 2018;12(4):99109. DOI: $10.17323 / j . j c f r .2073-0438.12 .4 .2018 .99-109$ 